\title{
Aspectos REgULATORIOS DE LA PROTECCIÓN JURÍDICA DE LA PRIVACIDAD Y DE LOS DATOS PERSONALES EN BRASIL
}

\section{REGULATORY ASPECTS OF THE LEGAL PROTECTION OF PRIVACY AND PERSONAL DATA IN BRAZIL}

\author{
Thiago Paluma* \\ José Luiz De Moura Faleiros Júnior**
}

Trabajo recibido el 3 de marzo de 2019 y aprobado el 3 de junio de 2019

\begin{abstract}
Resumen
La definición de marcos regulatorios para la protección de la privacidad y para la tutela jurídica de los datos personales ha sido una meta permanente en los diversos ordenamientos jurídicos, marcadamente a la luz de nuevos desafíos y perspectivas derivadas de la interacción entre el derecho y la tecnología. En Brasil, varias normas han surgido con el propósito de asignar solución jurídica a las nuevas contingencias derivadas de la presencia de la tecnología y, especialmente, de Internet, en la vida en sociedad. Se discute, a partir de esta constatación, la dificultad enfrentada por el derecho para la pacificación de esos nuevos conflictos, teniendo en cuenta la disparidad con que la evolución jurídica se da en relación a los avances tecnológicos. La hipótesis de trabajo parte del supuesto de que la definición de marcos regulatorios es importante para delimitar protecciones más direccionadas, pero no es suficiente para la garantía de la integral protección a derechos fundamentales en la sociedad de la información. El objetivo general del trabajo es avanzar más allá de la reproducción de conceptos contenidos en las recientes legislaciones brasileñas y, en líneas más específicas, destacar el verdadero alcance protector deseado para la amplia protección de la privacidad y para la adecuada tutela de los datos personales. La investigación utilizará el método de abordaje histórico-sociológico, con análisis bibliográfico-doctrinaria. Al final, se presentarán las consideraciones finales, de las cuales se procurará extraer una comprensión más asertiva en relación a la problemática explicitada.
\end{abstract}

Palabras clave: Derecho digital, Internet, Marcos regulatorios brasileños.

\footnotetext{
Abstract

The definition of regulatory frameworks for the protection of privacy and the legal protection of personal data has been a perennial goal in the various legal systems, markedly in the light of new challenges and perspectives arising from the interaction between law and technology. In Brazil, various norms have

* Thiago Paluma. Doctor en Derecho Internacional por la Universidad de Valencia, España. Maestro en Derecho por la Universidad Federal de Uberlandia. Profesor de la Facultad de Derecho de la Universidad Federal de Uberlandia-Brasil. Autor de diversos artículos y libros. Director de Innovación de la Universidad Federal de Uberlandia (2017-2020). Coordinador de grupos de investigación de la Academia Brasileira de Direito Internacional. Correo de contacto: thiago.paluma@ufu.br

** José Luiz De Moura Faleiros Júnior. Abogado, Maestría en Derecho por la Universidad Federal de Uberlandia-Brasil. Especialista en Derecho Procesal Civil, Derecho Civil y Empresarial, Derecho Digital y Compliance por la Facultad de Derecho. Damasio de Jesús. Abogado. Correo de contacto: juniorfaleiros@outlook.com. http://orcid.org/0000-0002-0192-2336
} 
arisen with the purpose of assigning legal solution to the new contingencies derived from the presence of technology and, especially, the Internet, in life in society. From this observation, the difficulty faced by the law for the pacification of these new conflicts is problematic, given the disparity with which legal developments take place in relation to technological advances. The working hypothesis assumes that the definition of regulatory frameworks is important to define more targeted protections, but it is not enough to guarantee the integral protection of fundamental rights in the information society. The general objective is to move beyond the reproduction of concepts contained in recent Brazilian legislation and, in more specific lines, to highlight the true protection scope aimed at broad protection of privacy and adequate protection of personal data. The research will use the method of historical-sociological approach, with bibliographical-doctrinal analysis. Finally, the final considerations will be presented, from which a more assertive understanding of the explicit problem will be extracted.

Keywords: Digital right. Internet. Brazilian regulatory frameworks.

\section{INTRODUCCIÓN}

La génesis de Internet, a partir de los incrementos tecnológicos, se remonta al Siglo XX y al inicio del fenómeno de la globalización, en el cual las corporaciones pasaron a integrarse dinámicamente en transacciones internacionales, provocando la nueva sistemática corporativa vislumbrada hasta los tiempos más recientes.

A lo largo de varias eras, la integración computacional y la facilitación del acceso de los ciudadanos al ambiente virtual propiciaron la captación de un volumen de informaciones, de forma estructurada o no, formando lo que se convenció llamar de big data. Sin embargo, la gran preocupación que surge no se refiere a la cantidad de datos, sino al trato dispensado por las grandes corporaciones a las informaciones, demandando intervenciones estatales para reglamentar ciertas relaciones jurídicas y proteger derechos fundamentales.

Además, se debe considerar que la mayoría de los ciudadanos ni siquiera saben la cantidad de datos personales suyos que están disponibles en la web y que pueden ser utilizados para fines ilícitos o abusivos, en flagrante violación a la privacidad. Por esta razón, la creación de marcos regulatorios se presenta como mecanismo necesario para asegurar la plena libertad del individuo en la sociedad de la información, reequilibrando la asimetría informacional causada por el intenso uso de datos personales y, aún, visando el favorecimiento del flujo de datos personales entre entidades que respeten las garantías del ciudadano sobre sus propios datos.

En este contexto se han editado importantes regulaciones en Brasil, siendo la primera de ellas la Ley no 12.965, del 23 de abril de 2014 (el "Marco Civil de Internet") y, posteriormente, el Decreto no 8.771 / 2016, que la reguló. Y, más recientemente, la Ley no 13.709, de 14 de agosto de 2018 (la "Ley General de Protección de Datos"), posteriormente modificada por la Medida Provisional no 869, del 27 de diciembre de 2018.

Sin embargo, la existencia de regulaciones preliminares de Internet en el país no agota el tema, porque no son raros los ejemplos de nuevas contingencias y desafíos a la tutela jurídica de derechos fundamentales, que enfrentan carencia de delimitación axiológica cuando son necesarios para dar solución a las más variadas relaciones virtuales.

Evidentemente, el llamado 'derecho digital' reúne una serie de temas de las más diversas ramas del

PALUMA, Thiago; LUIZ DE MOURA FALEIROS JÚNIOR, José. Aspectos regulatorios de la protección jurídica de la privacidad y de los datos personales en Brasil. Revista Justicia y Derecho, Santiago, v. 2, no 1, 2019 
derecho, siendo desafiado a la resolución de innumerables problemas contemporáneos. En ese sentido, el problema investigado parte de la necesidad de investigar la suficiencia de los marcos regulatorios para la pacificación social a partir de la tutela de los mencionados conflictos; a su vez, la hipótesis de investigación encuentra justificación en la necesidad de que se establezcan directrices sólidas para la implementación de las políticas de protección de datos personales definidas en la legislación, especialmente con el objetivo de prevenir demandas y responsabilidades.

La investigación utilizará el método de abordaje histórico-sociológico, con análisis bibliográfico-doctrinaria. Al final, se presentarán las consideraciones finales, de las cuales se procurará extraer una comprensión más asertiva en relación a la problemática explicitada.

\section{RELACIONES JURÍDICAS EN LA SOCIEDAD DE LA INFORMACCIÓN}

Las interacciones concernientes al mundo virtual se traducen en una dinámica de frenos y contrapesos diametralmente diversa de la que se observa en el plano real, especialmente por la presencia de la informática y de su evolución con la creación de Internet y con el fenómeno de la globalización.

En nuestros tiempos, se habla de una 'sociedad de la información', concepto desdoblado de la noción de sociedad en red. Y hay cierta controversia sobre los orígenes de la expresión, porque hay autores que defienden que fueron nombres norteamericanos de la década de 1960, como Fritz Machlup, los primeros en vislumbrar una futura sociedad en la que la información sería crucial para determinar la extensión de las inter-relaciones humanas; sin embargo, hay quienes defienden haber sido nombres japoneses, como Yoneji Masuda y Yujiro Hayashi, los primeros en hablar en una sociedad de 'base informacional' (情報 化 社会, o jōhōka shakai en la transliteración de los kanjis)'. No obstante, se atribuye a Jan van Dijk, famoso sociólogo holandés, la autoría de la expresión 'The Network Society² (De Netwerkmaatschappij, en holandés), extraída de su obra homónima publicada en 1991 y que inspiró a otro famoso sociólogo: el español Manuel Castells, que profundizó conceptos en su obra "The Rise of the Network Society", la primera parte de una trilogía denominada "The Information Age".

Otros nombres tuvieron también su papel en la definición de este concepto, a ejemplo de Zbigniew Brzezinski, que trabajó el concepto de 'sociedad tecnotrónica'4, o de Joseph Lasica, que previó formas como los seres humanos alimentarían un universo formado por datos variados, que modificarían la "propia naturaleza del diálogo humano"5.

En el auge de la era Industrial, cuando primero se consideró esta terminología, el uso de la electricidad propició avances impares. Además, se desarrolló el telégrafo y la radio, que posibilitaron el estrechamiento de las relaciones entre las personas y la agregación más rápida de las informaciones, en paralelo al avance de la fotografía, del cine y, finalmente, de la televisión. Todo esto llevó a la circulación más rápida de la información, y a partir de eso surgió la informática, dando origen a lo que Klaus Schwab llamó 'cuarta revolución industrial's, o a la proposición de una Lex Informatica, por el norteamericano Lawrence Lessig’.

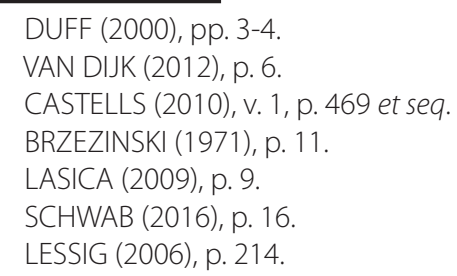

PALUMA, Thiago; LUIZ DE MOURA FALEIROS JÚNIOR, José. Aspectos regulatorios de la protección jurídica de la privacidad y de los datos personales en Brasil. Revista Justicia y Derecho, Santiago, v. 2, n 1, 2019 
Para José de Oliveira Ascensión, la sociedad de la información se compone de elementos relativos a programas de computadora, circuitos integrados, bases de datos electrónicos y utilización de obras por ordenador, representando no un concepto técnico, sino un eslogan, pues, en sus palabras, "sería (...) mejor hablar en sociedad de la comunicación, y sólo en un sentido muy amplio se puede calificar todo mensaje como información"8.

La incesante búsqueda por el aumento de las cadenas productivas y por el fortalecimiento empresarial, fueron las principales fuerzas motrices que culminaron en el surgimiento de instrumentos para el tratamiento automático y racional de la información, que se tornó, paulatinamente, el elemento de mayor importancia para el apalancamiento productivo en el período después de la revolución industrial ${ }^{9}$.

En este contexto, la informática surgió como elemento de avance de las prácticas de catalogación y procesamiento de datos, siendo el UNIVAC I el primer modelo de microcomputadora comercial, lanzado en $1951^{10}$ y evolucionando hasta mediados de la década de 1970, cuando surgió el microprocesador y empresas del lo que hoy se llama Valle del Silicio tuvieron origen, a partir de ideas que cambiarían el mundo.

En el año 1973, se desarrolló ARPANET, una red militar originada a partir de investigaciones de la Agencia de Proyectos de Investigaciones Avanzadas - ARPA (Advanced Research Projects Agency) del Departamento de Defensa de EEUU'11.

Con la implementación de las computadoras en las rutinas empresariales, el Siglo XX fue marcado por el incremento de la técnica y por la necesidad de desarrollar frenos para dosificar la alta capacidad de producción de los chips, propulsada gracias a la denominada "Ley de Moore"12, el fundamento principal de teorías fundamentales de la disciplina consumerista actual, como la obsolescencia programada. Erik Jayme, por ejemplo, destaca la extinción de las fronteras en la sociedad de la información, en la medida en que "cualquiera puede fácilmente liberarse de las amarras de su existencia limitada: velocidad, ubicuidad, libertad; el espacio, para la comunicación, ya no existe"13.

El concepto de ciberespacio, analizado a fondo por Pierre Lévy ${ }^{14}$, es un ambiente en el que se "operan y se autoproducen reglas sociales de comportamiento suyas y propias"15, y es innegable que el avance creciente del ritmo de producción y de la capacidad de procesamiento computacional encontraría los límites en la desintegración de los microcomputadores que, aunque cada vez más potentes y con costos equilibrados de producción, pero cercenados por la inviabilidad del intercambio informacional, demandaría investimentos y un crecimiento de la difusión de esos equipamientos para la población en general.

El crecimiento de grandes corporaciones, como Intel, IBM y, especialmente, Microsoft, cambiaron toda la dinámica social en la segunda mitad del siglo XX, cuando las computadoras pasaron a ocupar una posición necesaria en las relaciones empresariales y para el aumento de la productividad individual y corporativa. Ya se sabía del advenimiento de la hoy llamada Internet, cuyas bases se remontan a los experimentos realizados en la Organización Europea para la Investigación Nuclear (CERN, por su sigla en inglés), en 1980, por el físico británico Timothy “Tim" Berners-Lee, que sugirió la fusión de hipertextos

\footnotetext{
$8 \quad$ ASCENSÃO (2001), p. 67.

9 KANAAN (1998), pp. 23-31.

10 PINHEIRO (2016), p. 61.

11 LEONARDI (2005), pp. 3-4.

12 KEEN (2018), p. 11.

13 JAYME (2003), p. 134.

14 LÉVY (2010).

15 ROSSELLO (2010), p. 618.
}

PALUMA, Thiago; LUIZ DE MOURA FALEIROS JÚNIOR, José. Aspectos regulatorios de la protección jurídica de la privacidad y de los datos personales en Brasil. Revista Justicia y Derecho, Santiago, v. 2, no 1, 2019 
para crear el lenguaje HTML (HyperText Markup Language), que junto con el protocolo TCP (Transmission Control Procotol) y el llamado Sistema de Nombres de Dominio o DNS (Domain Name System) funcionan como la base estructural de World Wide Web (WWW), posteriormente bautizada de Internet ${ }^{16}$.

Bill Gates, Nathan Myhrvold y Peter Rinearson, en su renombrada obra "El camino del futuro", ya destacaban el papel que la Internet desempeñaría en el siglo XXI ${ }^{17}$, aunque durante la década de 1990 el movimiento de datos fuera pequeño, con pocas imágenes, textos y gráficos intercambiados en un sistema aún rudimentario y poco interconectado (llamado "web 1.0").

Con la transición a la llamada "web 2.0", la Internet adquirió una dimensión jurídica fundamental debido a la intensificación del intercambio de datos y la masificación de su uso por los individuos.

Según Ronaldo Lemos:

Dessa forma, o emprego desse método acopla-se à premissa sociológica de crise de paradigmas antes descrita, bem como ao caminho intermediário proposto como forma de investigação. Ficam de fora esforços enciclopedísticos ou classificatórios de pouca relevância prática, já que estes têm valor somente para a dogmática. O objetivo é enfrentar as transformações do direito em face do desenvolvimento tecnológico dentro da teoria geral do direito, mas de uma perspectiva de resolução prática de problemas, e não de reorganização lógico-formal de conteúdos jurídicos de pouca ou nenhuma consequência prática. O critério para a realização da crítica proposta leva em consideração caracteres interdisciplinares como forma de analisar institutos jurídicos do ponto de vista dos interesses econômicos, políticos etc., congregados por ele. Também como exemplo, o próprio critério de aprofundamento dos temas mapeados é político, e não se deriva de qualquer preceito lógico-formal'18.

La problemática explicitada por el autor, como es evidente, no se encierra en la "web 2.0", pues hay muchos otros cambios que se inician y que se operarán a corto y medio plazo. Ya se está en la era de la llamada "web 3.0", marcada por la operabilidad de la red en tiempo real, por la web creativa, por la tecnología tridimensional y por los avatares virtuales, dando origen a la "web semántica" que permitirá la red legible por máquinas y no más sólo por seres humanos ${ }^{19}$. Además, varios autores ya indican que se está caminando hacia la "web 4.0" o "web inteligente", marcada por la presencia de la 'Internet de las Cosas'20.

Según Eduardo Magrani, el advenimiento de la "web 3.0", que marcaría la actual etapa de la sociedad de la información, avanza a pasos agigantados en el contexto de la Internet de las Cosas (Internet of Things, o IOT), que también se sitúa en la frontera de la "web 4.0" o Internet de Todas las Cosas (Interent of Everything, o $(O E)$, momento en el que los gadgets y equipos electrónicos, además de automóviles e electrodomésticos estarán, por sí mismos, en conexión con la gran red, siendo capaces de practicar actos jurídicos a partir de la inteligencia artificial e de generar inclusión social21. Se experimenta un agravante, aún, debido a la circunstancia de que los usuarios de Internet son susceptibles a la rastreabilidad de sus pasos y acciones en el mundo virtual, siendo con frecuencia privados de elegir la técnica de obtención de datos y las informaciones que serán recogidas a su respecto ${ }^{22}$.

Los autores como Karan Patel ya sostienen la génesis de una “web 5.0", o 'web simbiótica', en la que se podría integrar gradualmente las tecnologías al propio ser humano, contemplando hasta sentimientos y

\footnotetext{
16 PINHEIRO (2016), pp. 61-63.

17 GATES et al., (1995), pp. 145-173.

$18 \operatorname{LEMOS}$ (2005), pp. 11-12.

19 KWANYA et al., (2015), pp. 33-37.

20 GREENGARD (2015), pp. 188-189.

21 MAGRANI (2018), pp. 72-73.

22 ROUTIER (2003), p. 154.
}

PALUMA, Thiago; LUIZ DE MOURA FALEIROS JÚNIOR, José. Aspectos regulatorios de la protección jurídica de la privacidad y de los datos personales en Brasil. Revista Justicia y Derecho, Santiago, v. 2, no 1, 2019 
emociones o transformando la web en un 'cerebro en paralelo'23, idea relativamente distópica, pero que no deja de ostentar relevancia, siendo además averiguada por Yuval Noah Harari².

Innegablemente, los avances de Internet y las numerosas nuevas tecnologías suscitan, también, nuevos conflictos, que se originan de las más variadas formas y seguirán surgiendo a un ritmo aún más constante, ya que los problemas de la sociedad de la información se derivan de la incapacidad de las personas de reaccionar a la rápida transformación tecnológica - y, con el derecho, no es diferente.

Notablemente, al buscar alcanzar su etapa más avanzada, de la creación del conocimiento masivo, la informatización posibilitará a todas las personas crear conocimientos y buscar su autorrealización. Siendo el ordenador una máquina lógica, equipada con las tres funciones de procesamiento de la información: memoria, computación y control, que aumenta sustancialmente la capacidad humana de procesar datos para producir información, las relaciones jurídicas se operarán de forma cada vez más frecuente por el ambiente virtual, irradiando los más diversos efectos.

El e-commerce, por ejemplo, resignificó el funcionamiento de las contrataciones electrónicas en las relaciones de consumo. Esto, sin embargo,"no puede privar al consumidor de la protección que le otorgan las disposiciones imperativas de la ley"25.

Según Caitlin Mulholland,

(...) uma vez estabelecida a proteção e defesa constitucionais do consumidor e determinada a tutela do efetivo acesso àjustiça aos consumidores, partes vulneráveis de uma relação de consumo, necessariamente, deve-se desconsiderar a regra conflitual do locus regit actum, e estabelecer-se a necessidade da tutela dos interesses do consumidor acima de qualquer outro critério conflitua ${ }^{26}$.

El llamado 'derecho al olvido' es otra de esas contingencias que desafían a los operadores del derecho, pues la propia idea de identidad pasa a ser revisitada en este nuevo panorama. Sobre eso, Sérgio Branco todavía instiga el debate al destacar que:

"Mensagens trocadas no Facebook, no Instagram e no WhatsApp são privadas, assim como podem ser privadas anotações feitas no Google Docs ou Evernote. Muitos vídeos podem ser inseridos no Youtube ou Vimeo com senha para acesso. Alguns blogs podem funcionar como verdadeiros confessionários por meio de pseudônimo ou simplesmente porque seu autor o mantém sigiloso.

Mas essa situação não é bastante semelhante à conservação de diários e cartas, cadernetas, agendas, bilhetes e anotações? Não necessariamente, pela expectativa de sigilo de tais documentos"27.

Se vive, pues, una nueva era social, con nuevos horizontes y perspectivas que buscan denotar nuevas dinámicas para la vida en sociedad, a partir de un análisis crítico de fenómenos como la virtualización de las relaciones e interacciones complejas, así sintetizadas por Juliano Madalena:

O novo reconduziu o homem para horizontes inovadores, abandonando caminhos ultrapassados e que levaram o sujeito à diluída sociedade pós-moderna, já em desuso, e, também, superada pela tecnologia. Se a pós-modernidade, ainda que fundada em uma grande opacidade conceitual, demarcou o consumo, a desconexão do sujeito, do abandono do moderno e da transformação do tempo. Assim, atualmente podemos assumir que vivemos na sociedade do hiper ${ }^{28}$.

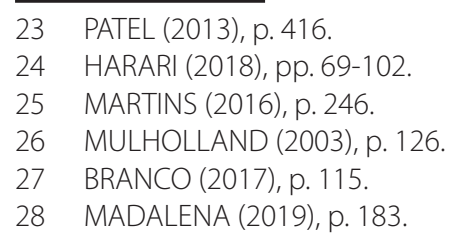

PALUMA, Thiago; LUIZ DE MOURA FALEIROS JÚNIOR, José. Aspectos regulatorios de la protección jurídica de la privacidad y de los datos personales en Brasil. Revista Justicia y Derecho, Santiago, v. 2, n 1, 2019 
En otro sentido, en ese contexto de una sociedad de hiperinformación, surge el fenómeno del "no olvido"y, con él, riesgos y nuevos desafíos que pasarán a ser enfrentados por el derecho en la resolución de $\operatorname{conflictos}^{29}$, siendo de curial importancia alertar para el hecho de que la sociedad contemporánea se relaciona de modo inédito con la información que produce de la misma forma como sus integrantes acceden ese mismo contenido con intensidad y amplitud ${ }^{30}$.

Otras situaciones sorprendentes, como la condena de un administrador de grupo de WhatsApp, desafían la doctrina a repensar "el hecho de tercero - causa excluyente de la responsabilidad civil - y sus implicaciones para la responsabilidad" ${ }^{\prime \prime}$. Sin embargo, no se puede dejar de mencionar las instigaciones para que juristas busquen comprender mejor "sobre la naturaleza jurídica de los nombres de dominio, analizando los principales tipos de conflictos existentes y los medios alternativos para solucionarlos" ${ }^{132}$. No obstante, hay muchos otros ejemplos, y, por regla general, la tutela de la privacidad y la protección de datos personales será el elemento común de la protección deseada.

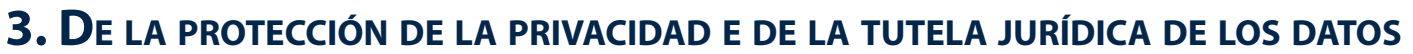 PERSONALES}

La incesante evolución de la integración computacional condujo a la formación del big data, imponiendo gran preocupación en lo que se refiere no sólo a la cantidad de datos, sino al tratamiento dispensado por las grandes corporaciones a las informaciones recogidas, tratadas y almacenadas en sus bases de datos.

El desconocimiento de los ciudadanos en relación a las operaciones de recolecta, tratamiento y almacenamiento de estos datos conduce a la necesidad de que sean creados marcos regulatorios como mecanismos necesarios para asegurar la plena libertad del individuo en la sociedad de la información. En este contexto, merecen ser destacadas la iniciativa europea denominada General Data Protection Regulation (GDPR), editada en el 27 de abril de 2016 y implementada en el 25 de mayo de 2018, y, en Brasil, la Ley no 13.709, de 14 de agosto de 2018 (la Lei Geral de Proteção de Dados, o LGPD), que será mejor analizada en los tópicos subsiguientes, con el objetivo de se cuestionar la finalidad de los marcos regulatorios.

En efecto, la doctrina busca investigar el alcance de esa protección normativa, y nombres como Danilo Doneda suscitan la búsqueda de la "promoción de un equilibrio entre los valores en cuestión, desde las consecuencias de la utilización de la tecnología para el procesamiento de datos personales, consecuencias para el libre desarrollo de la personalidad, hasta su utilización por el mercado".33 Por su parte, el marco de la protección de datos personales nace como un contrapunto necesario a la privacidad, siendo ponderada por Bruno Bioni la necesidad de protección del libre desarrollo de la personalidad como una libertad positiva, en contraposición a la propia privacidad, vista como una libertad negativa ${ }^{34}$.

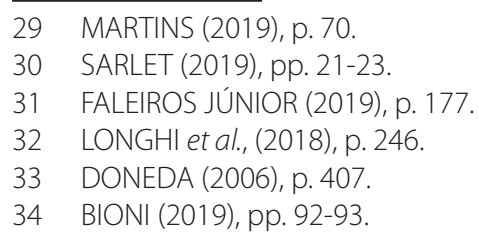

PALUMA, Thiago; LUIZ DE MOURA FALEIROS JÚNIOR, José. Aspectos regulatorios de la protección jurídica de la privacidad y de los datos personales en Brasil. Revista Justicia y Derecho, Santiago, v. 2, no 1, 2019 


\section{LOS MARCOS REGULATORIOS BRASILEÑOS}

Debido al incremento constante en el uso de Internet como herramienta de comunicación y de interacción social, surgieron diversas cuestiones desafiantes para la disciplina jurídica, puesto que se verificó la necesidad de reglamentar los derechos, deberes y responsabilidades en el uso de la red, con atención a las peculiaridades de ese ambiente "virtual"35, además de delimitar protecciones más específicamente orientadas a la privacidad y a los datos personales.

El desarrollo tecnológico ha cambiado drásticamente las relaciones comerciales y el mercado, que hoy se diversifica entre el medio físico y el medio digital, con ejemplos variados de empresas que actúan en uno y otro, e incluso de otras situaciones específicas que se dirigen exclusivamente al medio digital.

En este contexto, nuevas directrices jurídicas pasan a permear los modelos de negocio de esas compañías, que necesitan estar atentas a la realidad del mercado consumidor y a todas las diversas disciplinas jurídicas que les exigen un actuar en conformidad al Derecho. Es en este sentido que el legislador brasileño viene buscando, en el curso de los recientes años, asignar regulaciones especialmente orientadas a Internet.

\subsection{Marco Civil de Internet}

La reglamentación de elementos esenciales de las relaciones jurídicas se revela como un aspecto importantísimo no sólo para las empresas que desarrollan actividades con extensión o exclusivamente en medio digital, sino para todas, una vez que el trato con la tecnología avanza cada vez más, pasando a influenciar todos los modelos de negocio.

Los escándalos de grandes proporciones mediáticas, como los escapes denunciados por Edward Snowden ${ }^{36}$, que acusaba a la National Security Agency (NSA) de captar y tratar millones de llamadas telefónicas, despertó la atención del mundo para la necesidad de dar a Internet tratamiento jurídico más específico, etc.

Además, el hecho de que grandes corporaciones como Google Inc. y Facebook Inc. hagan uso de Internet para ofrecer publicidad más personalizada y dar salida a nuevos modelos de negocio ha despertado la necesidad de un marco regulatorio ${ }^{37}$.

Los ejemplos a ser citados son la protección de datos personales y la seguridad de la información, que son dos caras de una misma moneda, aunque esta esté conectada a los postulados de confidencialidad, integridad y disponibilidad. Esto porque hay varias noticias de escapes de información que parten de innumerables portales creados para atender a las más diversas finalidades. Por esta razón, esta nueva realidad virtual propició el acceso a datos de usuarios (datos personales), con relevancia impar, imponiendo a las compañías y organizaciones un celo especial por la seguridad de la información y la privacidad de los usuarios.

35 Este nuevo universo virtual es descrito por Saul Levmore y Martha Nussbaum como un fenómeno que hizo al ser humano inmerso en una nueva "pequeña villa", donde nadie más puede ser considerado un extraño. (LEVMORE, NUSSBAUM (2010), p. 1). 36 Andrew Keen analiza el episodio de Snowden destacando que la forma en que la recolección de datos se da en los tiempos actuales "significa que no existimos más", o al menos no de la misma manera que el derecho intrínseco a la privacidad era contemplado en el siglo XIX. (KEEN (2018), p. 11).

37 Esto es lo que destaca Tim Wu: "Google and a few other West Coast companies had demonstrated that web advertising wasn't just hype: there was real money to be made reselling attention captured by the Internet. But Google had effectively put AdWords on the remote control; there remained a lot more attention to be harvested the old-fashioned way. (...)". (WU (2016), p. 267).

PALUMA, Thiago; LUIZ DE MOURA FALEIROS JÚNIOR, José. Aspectos regulatorios de la protección jurídica de la privacidad y de los datos personales en Brasil. Revista Justicia y Derecho, Santiago, v. 2, n 1, 2019 
Las ideas de Lessig sobre la creación de una Lex Informatica o de un Code, como es el nombre de su principal obra, parten de la necesidad de delimitar cuatro grandes medios de regencia de los comportamientos y de normatización de conductas: la ley, como conjunto normativo del Estado; las normas sociales, que van más allá de los usos y costumbres y contemplan otras situaciones sociales contingentes; el mercado, como medio de acceso a bienes económicos; y la arquitectura, basada en los aspectos estructurales de los sistemas utilizados por esas corporaciones ${ }^{38}$.

En Brasil, el Comité Gestor de Internet en Brasil (CGI.br) fue el órgano que propulsó las discusiones que culminaron con la edición de la Ley no 12.965 / 2014 - el Marco Civil de Internet. Algunos principios divulgados por el CGI.br para definir las balizas de la gobernanza y del uso de la red fueron incorporados en el proceso de construcción del texto del PL n 2.126/2011, votado y aprobado en el Congreso Nacional para dar origen a la mencionada ley.

El Marco Civil de Internet tuvo por objetivo establecer principios, garantías, derechos y deberes para el uso de la red en el país, cuyo acceso es considerado un derecho del ciudadano, con una importancia incuestionable, en la medida en que se atribuyó tratamiento jurídico para la regulación de las relaciones digitales, especialmente en relación a temas como inclusión digital (artículo 27), exigencia de neutralidad de la red (artículo 90), protección de la intimidad y de la confidencialidad de los datos (art. 70, I, II, III), incluso con la exigencia de consentimiento expreso del usuario para la recolección, el uso, el almacenamiento y el tratamiento de datos personales (artículo 70, IX), y la garantía de la libertad de expresión, como fundamento del uso de Internet en Brasil (artículo 20).

Además, el Marco Civil ha contribuido al detallar las garantías típicas del derecho del consumidor aplicables a las relaciones en el ambiente digital, siendo este otro punto positivo de la norma (artículos 70, IV a VIII y XI a XIII).

Entre todos estos temas, la neutralidad de la red tal vez sea el de mayor impacto, en la medida en que tiene por objeto garantizar que todas las informaciones que transitan en la red sean tratadas de la misma forma, navegando a la misma velocidad, es decir, a la velocidad de la contratación, evitando que ciertas corporaciones se superpongan al propio Estado ${ }^{39}$. Es ese principio que garantiza la velocidad de acceso a cualquier tipo de información en la red y define las balizas de la privacidad, refrenando el poderío informativo de algunas pocas grandes corporaciones que definen aquello que Tim Wu denominó "Ios imperios de la comunicación"40.

Asimismo, el tratamiento conferido a la responsabilidad civil por la ley fue de fundamental importancia, en la medida en que no eran raras las decisiones judiciales condenando a los proveedores por su contenido, publicado por los usuarios de la red, por acción o omisión (responsabilidad por actos de terceros). Con el nuevo tratamiento jurídico de la materia, se pacificó el entendimiento aplicado al caso.

El derecho a la protección del honor y de la intimidad también fue contemplado en el tema de la responsabilidad civil, en la medida en que se definió el deber de remoción de contenidos mediante notificación extrajudicial, creando, con eso, tratamientos específicos para cada situación causante de daños.

Además, el carácter colaborativo del Marco Civil de Internet dio solución a diversos problemas jurídicos involucrando el uso de la red, garantizando, además, los principios regentes de su buen uso, con destaque para la neutralidad, siendo de curial importancia la lectura del artículo 10, §3ㅇ de la ley:

"Art. 10. A guarda e a disponibilização dos registros de conexão e de acesso a aplicações de internet de que

38 LESSIG (1999), p. 43.

$39 \operatorname{LLOYD}(1997)$, p. XXXIX.

40 WU (2010), pp. 255-257.

PALUMA, Thiago; LUIZ DE MOURA FALEIROS JÚNIOR, José. Aspectos regulatorios de la protección jurídica de la privacidad y de los datos personales en Brasil. Revista Justicia y Derecho, Santiago, v. 2, n 1, 2019 
trata esta Lei, bem como de dados pessoais e do conteúdo de comunicações privadas, devem atender à preservação da intimidade, da vida privada, da honra e da imagem das partes direta ou indiretamente envolvidas.

\section{$[\ldots]$}

$\S 3^{\circ}$. O disposto no caput não impede o acesso aos dados cadastrais que informem qualificação pessoal, filiação e endereço, na forma da lei, pelas autoridades administrativas que detenham competência legal para a sua requisição".

Se observa la atribución de competencia para la solicitud de datos catastrales personales (y, por lo tanto, sensibles) por "autoridades administrativas", sin, con todo, establecer quiénes son tales personas. Sin duda, la brecha normativo-regulatoria en relación a la competencia legal para solicitar y acceder a la información de los clientes abrió margen para que las personas no autorizadas puedan solicitar e acceder a datos personales, hiriendo, con eso, la intimidad y el honor de la persona que tiene sus datos expuestos, generando daños colaterales ${ }^{41}$.

Sin la definición clara de las mismas, la ley no tendrá su correcta aplicación y, por esa razón, no es posible precisar quiénes son las "autoridades administrativas" para el alcance definido por el Marco Civil de Internet. Y todo ese problema surgió a pesar de el propio Marco Civil de Internet delimitar, en su artículo 6, una especie de directriz hermenéutica ${ }^{42}$.

João Victor Rozatti Longhi todavía alerta acerca de la cuestión de la vigilancia:

O Marco Civil procura também evitar as práticas de vigilância que hoje compõem a estrutura do modelo de negócios de muitos provedores (bem como de instituições públicas), disciplinando a questão do registro e disponibilização de dados referentes à conexão e acesso a aplicações da Internet, constituindo ponto de partida à atual legislação específica sobre o tema, a lei geral de proteção de dados pessoais (lei no $13.709 / 18)^{43}$.

Se destaca, además, el hecho de que la reglamentación del Marco Civil - materializada en el Decreto no 8.771, de 11 de mayo de 2016, particularmente en su artículo 11 - no estableció quienes son las autoridades administrativas a que se refiere el artículo 10, §3․ del Marco Civil de Internet, y se limitó a hacer alusión al referido precepto normativo y establecer la obligatoriedad de motivación del acto de solicitud de datos catastrales o personales, lo que no llenó la brecha existente.

\subsection{Ley General de Protección de Datos}

El deber estatal de editar normas específicamente orientadas a la protección de daños personales viene de la necesidad de que sean creados derechos a los ciudadanos para que tengan control sobre sus datos, lo que contribuye para la disminución de la asimetría de informaciones y para la garantía de la seguridad jurídica y del fomento al desarrollo tecnológico y económico.

Además, importante informar que la consulta pública sobre el anteproyecto de Ley de Protección de Datos Personales fue realizada por la Secretaría Nacional del Consumidor (SENACON) en conjunto con la Secretaría de Asuntos Legislativos (SAL) a partir del proyecto denominado "Pensando el Derecho" del Ministerio de Justicia, que tiene el objetivo de promover, desde 2007, una participación más acentuada de la sociedad civil en la elaboración de textos legislativos y reglamentos en Brasil. Con eso, se busca crear normas más efectivas y conectadas con la realidad actual y con las demandas de los ciudadanos.

41 BAUMAN (2013), p. 108

42 STRECK (2014), p. 334.

43 LONGHI (2019), p. 127.

PALUMA, Thiago; LUIZ DE MOURA FALEIROS JÚNIOR, José. Aspectos regulatorios de la protección jurídica de la privacidad y de los datos personales en Brasil. Revista Justicia y Derecho, Santiago, v. 2, no 1, 2019 
Entre los días 28 de enero y 05 de julio de 2015, fue realizada una consulta pública que trató de los 52 artículos del texto propuesto en el anteproyecto, contando con varias contribuciones de los sectores público y privado, de la academia, de ciudadanos y organizaciones no-gubernamentales, que culminaron en la redacción final del Anteproyecto de la Ley de Protección de Datos, presentado el 20 de octubre de 2015.

El objetivo de la PL siempre fue disponer sobre el tratamiento de datos personales para la garantía del libre desarrollo de la personalidad y de la dignidad de la persona natural, siendo el texto resultante de un largo debate, iniciado en 2010 y retomado en 2014, bajo los cuidados de la Secretaría Nacional del Consumidor del Ministerio de Justicia.

Se observa, pues, que el Proyecto de Ley no 5276/2016 fue construido de forma colaborativa, con amplio compromiso social y por medio de dos consultas públicas realizadas a finales del año 2010 y a comienzos del año 2015, a partir de la iniciativa del Ministerio de Justicia de colocar el texto del Anteproyecto de la Ley de Protección de Datos Personales bajo escrutinio público.

En las palabras del proyecto, las operaciones realizadas con datos personales solamente podrían ocurrir mediante consentimiento inequívoco y por escrito del titular para el cumplimiento de una obligación legal, para la ejecución de políticas públicas, para la realización de investigación histórica, científica o estadística, garantizado, siempre que posible, el carácter anonimizado de los datos personales.

Además de estas hipótesis, tales operaciones podrían ocurrir cuando estrictamente necesarias para la ejecución de un contrato del cual es parte el titular, a pedido del mismo, para el ejercicio regular de derechos en proceso judicial o administrativo, para la protección de la vida o de la incolumidad física del titular o de tercero, para la tutela de la salud, con procedimiento realizado por profesionales del área de la salud o por entidades sanitarias.

En que pese el gran grado de detalle, la protección de datos ya existe en el ordenamiento patrio en diversos modales de la legislación infraconstitucional, a veces con naturaleza comercial y tributaria, a ejemplo de la confidencialidad de los agentes fiscales (artículo 198 del Código Tributario Nacional), de la grabación ambiental, e hasta mismo de lo Código de Defensa del Consumidor, que contiene previsiones relativas a los bancos de datos en las relaciones de consumo, y de la Ley Complementaria n. 105/2001, que permite a las autoridades administrativas romper la confidencialidad bancaria en determinadas situaciones ${ }^{44}$.

Al desdoblar el derecho a la protección de datos personales como derecho independiente del derecho fundamental a la privacidad, sin embargo, se pasa a tener una connotación de instrumentalidad del primero, lo que Danilo Doneda repudia, diciendo que la protección de la privacidad en el ordenamiento jurídico nacional "no podría estar limitada por esta, al mismo tiempo que hace referencias a toda gama de garantías fundamentales que se encuentran en el ordenamiento brasileño"45.

En este punto, es importante releer las palabras de Marshall McLuhan: "Al operar una sociedad con una nueva tecnología, el área que sufre la incisión no es la más afectada. El área de la incisión y del impacto se ve prejudicada. El sistema entero es el que cambia"46.

En ese sentido, era de esperar que un cambio sustancial en el panorama social, a partir de nuevas tecnologías que se vuelven más y más sensibles para la estructuración del ordenamiento, causara enormes impactos e impusiera una necesidad de repensar los riesgos de ella venidos - induciendo a la ya

44 LIMBERGER (2007), pp. 215-242.

45 DONEDA (2006), pp. 358-359.

46 MCLUHAN (2007), p. 84

PALUMA, Thiago; LUIZ DE MOURA FALEIROS JÚNIOR, José. Aspectos regulatorios de la protección jurídica de la privacidad y de los datos personales en Brasil. Revista Justicia y Derecho, Santiago, v. 2, no 1, 2019 
mencionada idea de vigilancia, que Stefano Rodotà analiza con gran profundidad ${ }^{47}$.

Aún en lo que se refiere a este tema, Zygmunt Bauman y David Lyon apuntan lo siguiente:

Os principais meios de obter segurança, ao que parece, são as novas técnicas e tecnologias de vigilância, que supostamente nos protegem, não de perigos distintos, mas de riscos nebulosos e informes. As coisas mudaram tanto para os vigilantes quanto para os vigiados. Se antes você podia dormir tranquilo sabendo que o vigia noturno estava no portão da cidade, o mesmo não pode ser dito da "segurança" atual. Ironicamente, parece que a segurança de hoje gera como subproduto - ou talvez, em alguns casos, como política deliberada? - certas formas de insegurança, uma insegurança fortemente sentida pelas pessoas muito pobres que as medidas de segurança deveriam proteger ${ }^{18}$.

No se niega la importancia de reglamentar la protección de la privacidad y de las operaciones de recolección, tratamiento y almacenamiento de datos. Por ese motivo, la doctrina se reporta reiteradamente a la expresión "acumulación de informaciones"49.

Richard Warner alerta sobre los riesgos de comprender algunos desdoblamientos de la privacidad, lo que acaba por demandar un comportamiento que la mayoría de los individuos simplemente no vislumbra como viable, teniendo en cuenta que los beneficios percibidos son, simplemente, demasiado bajos, lo que induce a un menosprecio por los propios datos ${ }^{50}$, que terminan siendo fácilmente cedidos en operaciones triviales como la creación de una cuenta en una plataforma cualquiera (una red social, un portal virtual de venta ao por menor, un proveedor e-mail, un feed de noticias, etc.).

La lección de Frank Pasquale es elucidativa:

Conhecimento é poder. Examinar os outros, evitando o escrutínio, é uma das formas mais importantes de poder. As empresas buscam detalhes íntimos da vida dos potenciais clientes e funcionários, mas fornecem aos reguladores o mínimo de informações possiveis sobre suas próprias estatísticas e procedimentos. As empresas de Internet coletam cada vez mais dados sobre seus usuários, mas combatem regulamentações que permitem que esses mesmos usuários exerçam algum controle sobre os dossiês digitais resultantes ${ }^{51}$.

Europa salió adelante con el Reglamento no 2.016 / 679, generalmente conocido como "Reglamento General sobre Protección de Datos" - RGPD (o GDPR, por su sigla en inglés), marco regulatorio que pretendeu reforzar y hacer más cercanos de la realidad actual institutos considerados avanzados, como el derecho a borrar datos, el derecho al olvido, además de contener normas que van más allá de las ya establecidas autoridades de protección de datos en cada uno de los países, disciplinando el Comité Europeo de Protección de Datos ${ }^{52}$.

Brasil actuó meses después de la entrada en efecto de la legislación europea, y aprobó, en 2018, la Ley General de Protección de datos (Ley no 13.709, de 14 de agosto de 2018, comúnmente identificada por la sigla LGPD), con vigencia postergada inicialmente por 18 meses debido a la vacatio legis.

Sin embargo, debido a la existencia de algunos vetos presidenciales al texto final de la ley, en el final del gobierno anterior, se editó la Medida Provisional no 869, del 27 de diciembre de 2018, que ya trae

47 Confira-se: RODOTÀ, Stefano. A vida na sociedade da vigilância: a privacidade hoje. Trad. Danilo Doneda e Luciana Cabral Doneda. Rio de Janeiro: Renovar, 2008.

48 BAUMAN (2013), pp. 95-96.

49 SOLOVE (2008), p. 4.

50 WARNER (2011), p. 1084.

51 PASQUALE (2015), p. 4. En el original: "Knowledge is power. To scrutinize others while avoiding scrutiny oneself is one of the most important forms of power. Firms seek out intimate details of potential customers' and employees' lives, but give regulators as little information as they possibly can about their own statistics and procedures. Internet companies collect more and more data on their users but fight regulations that would let those same users exercise some control over the resulting digital dossiers".

52 EUROPA. Regulamento Geral de Proteção de Dados.

PALUMA, Thiago; LUIZ DE MOURA FALEIROS JÚNIOR, José. Aspectos regulatorios de la protección jurídica de la privacidad y de los datos personales en Brasil. Revista Justicia y Derecho, Santiago, v. 2, n 1, 2019 
alteraciones al texto de la ley, entre ellas una dilatación del plazo de vacatio legis para 24 meses, aumentando aún más el lapso para su entrada en vigor en lo que se refiere a la materia de protección de datos (artículo 65, inciso II).

Aún, se observa un debilitamiento de la protección de los datos académicos (artículo 40, II, "b"), que antes contaban con las protecciones de los artículos $7 \mathbf{0}$ y 11 , y que ahora integran las ya vagas nociones de "seguridad pública", "defensa nacional", "seguridad del Estado", etc. (artículo 4, III). También se alteró el concepto de "encargado" (artículo 50, VIII), que, antes, debería ser una persona natural y, en el nuevo texto, se ha pasado a permitir que tal función sea realizada por tratamiento automatizado de datos, con regencia por algoritmos que dan lugar a lo que Frank Pasquale llama "sociedad de la caja negra" ("black box society").

Aunque todavía esté en um período de vacatio legis, es cierto que la medida provisional retrocede con respecto a la redacción original de la Ley $n^{\circ}$ 13.709/2018, en la medida en que amplía las excepciones al sistema general de protección de los datos sensibles, basado, en última instancia, en el consentimiento informado, añadiendo al artículo 11, $\$ 40$, que restringe la comunicación o el uso compartido entre controladores de datos personales sensibles referentes a la salud con el objetivo de obtener ventajes económicas, excepto en dos hipótesis: (i) portabilidad de datos cuando consentido por el titular; o (ii) necesidad de comunicación para la adecuada prestación de servicios de salud suplementaria.

En relación a los datos del Poder Público (artículo 26, §10), hizo lo mismo, ampliando el rol de excepciones y facilitando, por consiguiente, su flujo fuera de las hipótesis en que hay consentimiento del ciudadano y dispensándose también la comunicación por parte del Poder Público en estas hipótesis (artículo 27).

Sin embargo, el punto fundamental de la MP fue la creación de la Autoridad Nacional de Protección de Datos y de lo Consejo Nacional (artículos 55-A y siguientes). A partir de esta innovación, se espera que finalmente se tenga una autoridad organizada y estructurada para suplir las brechas existentes desde el advenimiento del Marco Civil de Internet.

Con todo, diferentemente de la redacción original de la LGPD, en el texto de la versión de la Medida Provisional, que ya está en vigor en lo que se refiere a la creación de la ANPD (artículo 65, I), se ha definido que dicha autoridad nacional no será una entidad de la Administración Indirecta, pero órgano de la Administración Directa federal, lo que restringe su independencia - aspecto central de su concepción en la época del Anteproyecto.

\section{Consideraciones finales}

Consciente de ese breve escorzo concerniente a los marcos regulatorios brasileños sobre la tutela jurídica de Internet, se observa que las dos grandes leyes de regencia de la materia - Marco Civil de Internet, de 2014, y la Ley General de Protección de Datos, de 2018 - son meros embriones de un nuevo universo para el cual el derecho necesitará prepararse para dar cuenta de asignar solución jurídica a un sin número de nuevos conflictos y contingencias que vendrán de las incesantes innovaciones tecnológicas.

Se ve como elogiable la intención del legislador brasileño, pero el ritmo de avance del derecho no es capaz de acompañar la celeridad impar del desarrollo tecnológico, lo que pone en duda la efectividad de la tutela jurídica - especialmente para la protección de derechos fundamentales - en este nuevo contexto digital.

PALUMA, Thiago; LUIZ DE MOURA FALEIROS JÚNIOR, José. Aspectos regulatorios de la protección jurídica de la privacidad y de los datos personales en Brasil. Revista Justicia y Derecho, Santiago, v. 2, no 1, 2019 
Estudiar el fenómeno descrito como 'sociedad de la información' es uno de los elementos centrales para la superación de los desafíos que el futuro reserva y, sin duda, el establecimiento de marcos regulatorios normativos vale como punto inicial para la definición de un contexto protector que, por otro lado, no puede en esto agotarse.

\section{Bibliografía Citada}

Ascensão, José de Oliveira (2001): Direito da Internet e da sociedade da informação. (Rio de Janeiro, Forense).

BAuman, Zygmunt (2013): Danos colaterais: desigualdades sociais numa era global. Trad. Carlos Alberto Medeiros (Rio de Janeiro, Zahar).

Bauman, Zygmunt; Lyon, David. Vigilância líquida (2013) Trad. Carlos Alberto Medeiros (Rio de Janeiro, Zahar).

Bıonı, Bruno Ricardo (2019): Proteção de dados pessoais: a função e os limites do consentimento (Rio de Janeiro, Forense).

Branco, Sérgio (2017): Memória e esquecimento na Internet (Puerto Alegre, Arquipélago Editorial).

BrzEZINSKI, Zbigniew K. (1971): Between two ages: America's role in the technetronic era (Nueva lork, Viking Press).

CASTELLS, Manuel (2010): The rise of the network society: information age (Oxford, Blackwell, 2a edición, v. 1).

DonedA, Danilo (2006): Da privacidade à proteção de dados pessoais (Rio de Janeiro, Renovar).

Duff, Alistair A. (2000): Information society studies (Nueva York, Routledge).

FaleIROS JúNIOR, José Luiz de Moura (2019): A responsabilidade civil do administrador de grupo de WhatsApp, en MarTins, Guilherme Magalhães; LongHI, João Victor Rozatti (Coords.), Direito digital: direito privado e internet (Indaiatuba, Foco, 2a ed.).

Gates, Bill; Myhrvold, Nathan; Rinearson, Peter (1995): A estrada do futuro. Trad. Beth Vieira, Pedro Maia Soares, José Rubens Siqueira e Ricarco Rangel (San Pablo, Cia. das Letras).

GreEngaRD, Samuel (2015): The internet of things (Cambridge, The MIT Press).

Hararl, Yuval Noah (2018): 21 lições para o século 21. Trad. Paulo Geiger (San Pablo, Cia. das Letras).

JAYME, Erik (mar. 2003): O direito internacional privado do novo milênio: a proteção da pessoa humana face à globalização. Cadernos do Programa de Pós-Graduação em Direito - PPGDir./UFRGS (Puerto Alegre), v. 1, n. 1, p. 133-146.

KanaAn, João Carlos (1998): Informática global (San Pablo, Pioneira, 2a ed.).

KeEN, Andrew (2018): How to fix the future (Nueva York, Atlantic).

Kwanya, Tom; StILwell, Christine; Underwood, Peter G. (2015): Library 3.0: Intelligent Libraries and apomediation (Oxford, Chandos/Elsevier).

LASICA, Joseph D. (2009): Identity in the age of cloud computing (Washington, The Aspen Institute).

PALUMA, Thiago; LUIZ DE MOURA FALEIROS JÚNIOR, José. Aspectos regulatorios de la protección jurídica de la privacidad y de los datos personales en Brasil. Revista Justicia y Derecho, Santiago, v. 2, no 1, 2019 
Lemos, Ronaldo (2005): Direito, tecnologia e informação (Rio de Janeiro, FGV).

LEONARDI, Marcel (2005): Responsabilidade civil dos provedores de serviços de Internet (San Pablo, Juarez de Oliveira).

LESSIG, Lawrence (2006): Code 2.0 (Nueva York, Basic Books, 2a ed.).

LESSIG, Lawrence (1999): Code and other laws of cyberspace (Nueva York, Basic Books).

Levmore, Saul; Nussbaum, Martha (2010): "Introduction", en Levmore, Saul; Nussbaum, Martha, The offensive Internet (Cambridge, Harvard University Press).

Lévy, Pierre (2010): Cibercultura. Trad. Carlos Irineu da Costa (San Pablo, Editora 34, 3a ed.).

LIMBERGER, Têmis (2007): O direito à intimidade na era da informática (Puerto Alegre, Livraria do Advogado).

LLoYD, Ian (1997): Information technology law (Londres, Butterworths, 2a ed.).

LoNGHI, João Victor Rozatti (2019): "Marco Civil da Internet no Brasil: breves considerações sobre seus fundamentos, princípios e análise crítica do regime de responsabilidade civil dos provedores", en MARTINS, Guilherme Magalhães; LongHI, João Victor Rozatti (Coords.), Direito digital: direito privado e internet (Indaiatuba, Foco, $2^{\mathrm{a}}$ ed.).

LongHI, João Victor Rozatti; Faleiros JúnIOR, José Luiz de Moura; Melo, Letícia Faturetto de (jan./jun. 2018): "O Sistema SACl-Adm e o papel da arbitragem na solução de conflitos digitais", Revista Publicum, Rio de Janeiro, v. 4, n. 1, p. 227-247.

MADAlenA, Juliano. "Regulação das fronteiras da Internet: um primeiro passo para uma teoria do direito digital", en MARTIns, Guilherme Magalhães; LonghI, João Victor Rozatti (Coords.), Direito digital: direito privado e internet (Indaiatuba, Foco, 2a ed.).

Magranı, Eduardo (2018): A internet das coisas (Rio de Janeiro, FGV).

MARTINS, Guilherme Magalhães (2016): Contratos eletrônicos de consumo (San Pablo, Atlas, 3a ed.).

MARTINS, Guilherme Magalhães (2019): "O direito ao esquecimento na Internet", en MARTINS, Guilherme Magalhães; LonGHI, João Victor Rozatti (Coords.), Direito digital: direito privado e internet (Indaiatuba, Foco, 2a ed.).

McluHAn, Marshall (2007): Os meios de comunicação como extensões do homem. Trad. Décio Pignatari (San Pablo, Cultrix).

Mulholland, Caitlin Sampaio (2013): Internet e contratação: panorama das relações contratuais eletrônicas (Rio de Janeiro, Renovar).

PASQuALE, Frank (2015): The black box society: the secret algorithms that control money and information (Cambridge, Harvard University Press).

Patel, Karan. "Incremental journey for world wide web: introduced with web 1.0 to recent web 5.0: a survey paper", International Journal of Advanced Research in Computer Science and Software Engineering, Jaunpur, v. 3, n. 10, p. 410-417, out.

PINHeIRO, Patrícia Peck (2016): Direito digital (San Pablo, Saraiva, 6a ed.).

RoDotà, Stefano (2008): A vida na sociedade da vigilância: a privacidade hoje. Trad. Danilo Doneda e Luciana Cabral Doneda (Rio de Janeiro, Renovar).

PALUMA, Thiago; LUIZ DE MOURA FALEIROS JÚNIOR, José. Aspectos regulatorios de la protección jurídica de la privacidad y de los datos personales en Brasil. Revista Justicia y Derecho, Santiago, v. 2, no 1, 2019 
Rossello, Carlo Riflessioni (2010). De jure condendo in materia di responsabilità del provider. II Diritto deII'Informazione e Dell'Informatica, Roma, v. 26, n. 6, p. 617-629, nov./dez. 2010.

Routier, Richard (2003): "Traçabilité ou anonymat des conexions?", en PEDrot, Philippe (Org.), Traçabilité et responsabilité (Paris, Economica).

Sarlet, Ingo Wolfgang; FerReira Neto, Arthur (2019): O direito ao "esquecimento" na sociedade da informação (Puerto Alegre, Livraria do Advogado).

Schwab, Klaus (2016): The fourth industrial revolution (Genebra, World Economic Forum).

Solove, Daniel J. (2014): Understanding privacy (Cambridge, Harvard University Press).

StreCK, Lenio Luiz (2014): "Apontamentos hermenêuticos sobre o Marco Civil regulatório da Internet" en Leite, George Salomão; Lemos, Ronaldo (Coords.). Marco Civil da Internet (San Pablo, Atlas).

Van DIJk, Jan (2012): The network society (Londres, Sage Publications,3a ed.).

WARNER, Richard (2011): "Undermined norms: the corrosive effect of information processing technology on informational privacy" Saint Louis University Law Journal, Saint Louis, v. 55, p. 1047-1086.

Wu, Tim (2016): The attention merchants: the epic scramble to get inside our heads (Nueva York, Vintage).

Wu, Tim (2010): The master switch: the rise and fall of information empires (Nueva York, Vintage).

\section{NORMAS CITADAS}

BRASIL. Lei no 12.965, de 23 de abril de 2014. Estabelece princípios, garantias, direitos e deveres para o uso da Internet no Brasil. In: Diário Oficial da República Federativa do Brasil, Brasília, DF, 24 abr. 2014. Disponible en: http://www.planalto.gov.br/ccivil_03/_ato2011-2014/2014/lei//12965.htm. Acceso en: 08 jan. 2019.

BRASIL. Lei no 13.709, de 14 de agosto de 2018. Dispõe sobre a proteção de dados pessoais e altera a Lei no 12.965, de 23 de abril de 2014 (Marco Civil da Internet). In: Diário Oficial da República Federativa do Brasil, Brasília, DF, 15 ago. 2018. Disponible en: http://www.planalto.gov.br/ccivil_03/_Ato2015-2018/2018/ Lei/L13709.htm. Acceso en: 08 jan. 2019.

BRASIL. Medida Provisória no 869, de 27 de dezembro de 2018. Altera a Lei no 13.709, de 14 de agosto de 2018, para dispor sobre a proteção de dados pessoais e para criar a Autoridade Nacional de Proteção de Dados, e dá outras providências. In: Diário Oficial da República Federativa do Brasil, Brasília, DF, 28 dez. 2018. Disponible en: http://www.planalto.gov.br/ccivil_03/_Ato2015-2018/2018/Mpv/mpv869.htm\#art1. Acceso en: 08 jan. 2019.

EUROPA. Regulamento Geral de Proteção de Dados. Disponible en: https://eur-lex.europa.eu/legal-content/PT/TXT/PDF/?uri=CELEX:32016R0679\&from=PT. Acceso en: 10 jan. 2019.

PALUMA, Thiago; LUIZ DE MOURA FALEIROS JÚNIOR, José. Aspectos regulatorios de la protección jurídica de la privacidad y de los datos personales en Brasil. Revista Justicia y Derecho, Santiago, v. 2, no 1, 2019 